\title{
A proposed framework for Cloud Computing adoption
}

\author{
Victor Chang \\ Xi'an Jiaotong Liverppol University, Suzhou, China \\ ic.victor.chang@gmail.com
}

\begin{abstract}
This paper presents a review related to Cloud Computing focusing on Cloud business requirements. From the review we recommend a number of methods managing Cloud services and evaluating its service performance, including the use of a pair of the Hexagon Models. Three organizational challenges of Cloud adoption are identified: (i) Organizational Sustainability; (ii) Portability and (iii) Linkage. The Cloud Computing Adoption Framework (CCAF) is designed to deal with these challenges by helping organizations to achieve good Cloud designs, deployment and services. How these three challenges are addressed by the CCAF is demonstrated using case studies. Services implemented by CCAF are reviewed using the Hexagon Models for comparison. This paper provides recommendations to help organizations, researchers and practitioners to understand Cloud business context, to measure their risk and return analysis, to migrate their services to Cloud from all types and to connect and integrate different services as a single service. Future direction and security concerns have been addressed in our framework.
\end{abstract}

Keywords: Cloud Computing Adoption Framework (CCAF); Recommendation for organizational challenges of Cloud adoption; Organizational Sustainability; Portability; Linkage; Business Integration as a Service (BIsaS); Hexagon Models.

\section{INTRODUCTION}

Since Year 2007 onwards, Cloud Computing has created positive impacts, business opportunities, large scale adoption and case studies for a growing number of users and organizations. Benefits include improvement in efficiency; offering added values for organizations; saving costs in operations, resources and staff - as well as new business opportunities for service-oriented models (Boss et al., 2007; Vouk, 2008; Briscoe and Marinos, 2009; Hayne, 2009; Schubert, Jeffery and Neidecker-Lutz 2010; Chang et al., 2010 a; 2010 b). In addition, it is likely that cloud computing which focuses on operational savings and green technology will be at the centre of attention in the near future.

There are academic and industrial efforts to define business models and profitability offered by Cloud. From academic perspective, Weinhart et al. (2009 a; 2009 b) propose their Cloud Business Model and suggest Cloud can offer business opportunities and profitabilities. Chou (2009) defines seven different business models for all types of organizations. Buyya et al. (2009) present Cloud economic models and demonstrate how SLA can be used for generating economic values. Buyya et al. (2010) also demonstrate applications and services developed for Cloud, and these services are helpful for start-up firms to generate additional revenues. Marston et al. (2010) describe detailed analysis of Cloud Computing business perspective, and present a table of a list of active players in providing Cloud products and services. They recommend their Cloud economics in their business-technology framework, where each Cloud service is rated high or low in terms of business and technology in their matrix.

From industrial perspective, there are an increasing number of organizations offering Cloud products and services. Amazon is a market leader in Public Cloud and offers Elastic Compute Cloud (EC2) for computing capacity and Simple Storage Service (S3) for storage capacity. Microsoft provides Windows Azure services to allow developers to store their codes and develop new applications for their clients or companies. Salesforce.com is a pioneer in Cloud and presents their Customer Relation Management (CRM) applications for a large number of their users. Oracle consolidates resources with Sun Microsystems, and offers several products and services ranging from hardware to application focus. IBM has Cloud products and applications suites to help their customers. In addition, there are more Small and Medium Enterprises (SME) developing and selling their Cloud services and products, and they offer different types of business models and perspective (Marston, et al., 2010). The structure of this paper is as follows. Section 2 presents benefits and characteristics of Cloud Computing. Section 3 explains Cloud Computing for 
business use and assets factors for successful Cloud business, which then leads to the introduction of the Hexagon Models in Section 4. Section 5 describes organizational challenges for Cloud adoption which needs a careful handling. As a result, a framework is required and is presented in Section 6. Section 7 explains the framework and the three elements, including the work for each element in details. Section 8 illustrates the conceptual diagram of the framework, whereby research contributions offered by each element of the framework are demonstrated presented in Section 9. Section 10 presents topics of discussions including the use of the Hexagon Models, and Section 11 sums up Conclusion and future work.

\section{BENEFITS AND CHARACTERISTICS OF Cloud}

There are several discussions about the benefits of adopting Cloud Computing, amongst which Schubert, Jeffery and Neidecker-Lutz (2010) provide the most relevant context. They divide benefits into non-functional, economic and technical aspects. However, some of their descriptions are duplicates of existing points. Their review (Schubert, Jeffery and Neidecker-Lutz, 2010; Chang, 2014) can be summarized as follows:

\section{NON-FUNCTIONAL (SCHUBERT, JEFFERY AND}

NEIDECKER-LUTZ, 2010; CHANG, 2014):

- Elasticity: This provides users flexibility in selecting the amount and size of data supported by an application or the number of concurrent users. Elasticity includes real-time reaction to changes in the number of requests and size of requested resources, as well as handling swift changes to demands and services. Agility and adaptability are considered as a subset of elasticity, which allows the dynamic integration and extraction and rapid scaling up and down of physical resources from the infrastructure.

- Quality of Service (QoS): QoS is the capability to guarantee services. Factors such as response time, throughput and so on must be guaranteed to ensure the quality guarantees of cloud users are met.

- Reliability: Reliability offers the capability to ensure constant operation of system without disruption including no loss of data, and is normally achieved via redundant resource utilization. It has close relations with availability except reliability focuses on prevention of loss.

- Availability: Availability is the ability to introduce redundancy for services and data so failures can be masked transparently. This can be enhanced by replication of data and services to distribute them across different resources for load-balancing, and thus it can be regarded as the origin of scalability for clouds.

\section{ECONOMIC (SCHUBERT, JEFFERY AND NEIDECKER-} LUTZ, 2010; CHANG, 2014):

- Pay per use: This allows pay-as-you-go style for the amount of resources and period used, without the need to pay for additional contractual costs, and without the need to buy and maintain servers. This provides great flexibility for SMEs and researchers to only pay for they use.

- Cost reduction: This allows organizations to save money from IT operations, since it provides outsourcing model, and the opportunity to scale down IT expenditure. For large organizations with internal infrastructure, it can reduce cost for infrastructure maintenance and acquisition by consolidating, reallocating and optimizing available resources.

- Return of investment (ROI): This allows SMEs to sell their services quickly and easily without delays caused by acquiring and building the infrastructure. It also allows organizations to offer outsourcing business models and services.

- Going Green: Using less resources and infrastructure reduces carbon footprint and emissions.

\section{TECHNOLOGICAL (SCHUBERT, JEFFERY AND \\ NEIDECKER-LUTZ, 2010; CHANG, 2014):}

- Virtualization: This is a core characteristic of Cloud, and the use of Virtual Machines (VM) and VM Consoles enable enhanced flexibility through routing, aggregation and translation. This offers additional advantages, including (i) ease of use; (ii) infrastructure independency; (iii) flexibility and adaptability; and (iv) location independence.

- Multi-tenancy: This is another core characteristic of Cloud that allows the same resources to be shared by multiple users, and shared resources such as data and applications to be made available in multiple isolated instances.

- Data and Storage Management: Data consistency must be maintained over a wide distribution of replicated resources, and systems must be mindful of latencies for data location and workload. Data management also needs consistency guarantees.

- APIs, metering and tools - APIs provide common programming models for developers to improve on scalability and autonomic capabilities. Tools are endproducts to support development, migration and usage of cloud services. A metering service is essential for elastic pricing, charging and billing. 
- Security, Privacy and Compliance - this is a crucial part and essential for all cloud systems and services.

Understanding these benefits help organizations for Cloud adoption, whether they go for public, private or hybrid Cloud. It helps organizations to reduce operational costs, improve efficiency, streamline the processes and mitigate operational risks to vendors (Briscoe and Marinos, 2009; Martson et al., 2010; Schubert, Jeffery and NeideckerLutz, 2010). Chang et al. (2010 f) demonstrate the costsaving is achieved and the improvement in user satisfaction in Cloud adoption by the University of Southampton.

Business Computing is an area linking both computing and businesses, and provides insights into how challenges can be resolved in the business context with improvements in efficiency, profitability and customer satisfaction (IBM SOA, 2008). Business Computing is closely related to Cloud, since Cloud Computing offers business opportunities and incentives (Schubert, Jeffery and Neidecker-Lutz, 2010). To understand how Cloud businesses can perform well with long-term organizational sustainability, having the right business models will be essential (Chou, 2009; Weinhart et al., 2009). There are eight Cloud business models classified by Chang et al. (2013), who explain the background, literature and rationale of Cloud business models categorization and benefits of using multiple business models.

\section{Cloud Computing for Business Use}

Several papers have explained IaaS, PaaS and SaaS as the cloud business model (Buyya et al. 2009; Chen, Wills, Gilbert, Bacigalupo, 2010; Armbrust et al., 2009; Weinhardt et al., 2009; Schubert, Jeffery and Neidecker-Lutz, 2010). Despite all having a slightly different focus, all of them are classified under "Service Provider and Service Orientation", regardless of whether they are IaaS, PaaS, or SaaS service providers, or their focus is on billing, or SLA or CRM, since this is a mainstream model that still has areas of unexploited opportunities. In addition, Cloud can offer substantial savings by reducing costs whilst maintaining high levels of efficiency (Oracle 2009; Schubert, Jeffery and Neidecker-
Lutz, 2010). In Oracle (2009) and Vmware (2010) scenarios, both propose "In-House Private Clouds" to maximize use of internal resources to obtain added value offered by Cloud while keeping costs low. This allows organizations to build their own to satisfy IT demands and maintain low-costs including private cloud development (Claburn 2009), and is a new model from a micro economic point of view (Hull, 2009). Successful business models are not restricted to particular sectors or areas of specialization and can be applicable for businesses including Cloud businesses. Table 1 below gives a summary of criteria and supporting papers.

To classify the business models and processes, Chang et al. (2010 a; 2010 c; 2010 e) classify all Cloud business models into eight types by using the Cloud Cube Model (CCM) proposed by The Jericho Forum (JM). They use $\mathrm{CCM}$ to represent the good practices in Cloud businesses supported by case studies and explain strengths and weaknesses in each business model. Collaborators and investors have found such recommendation useful. Table 2 shows advantages and disadvantages of eight Cloud business models (Chang et al., 2010 a). Chang et al. (2010 a; 2010 c; 2010 e) explain advantages and disadvantages of each of eight business models, whereby the multiple uses of Cloud business models can ensure greater benefits for organizations that adopt Cloud.

\subsection{HOW THESE BUSINESS MODELS HELP ORGANIZATIONS OF CLOUD ADOPTION}

Having the winning strategies also greatly influences decision-makers from traditionally non-cloud organizations. Wolfram is a computational firm providing software and services for education and publishing, and apart from using the CCM, it has considered adopting the second business model (HPC in the Cloud, 2010). Upon seeing revenues in iPhone and iPad, they added a new model, the eighth model, by porting their applications onto iPhone and iPad. Similarly MATLAB, adopted the first and second model, and began the eighth model by porting their application to iPhone and iPad in order to acquire more income and customers. 


\begin{tabular}{|l|l|}
\hline Criteria of Business Model Classification & Papers \\
\hline Service Provider and Service Orientation & $\begin{array}{l}\text { Buyya et al. (2009); Chen et al. (2010); Armbrust et al. (2009) } \\
\text { Weinhardt et al. (2009 a; 2009 b) } \\
\text { Schubert, Jeffery and Neidecker-Lutz (2010) }\end{array}$ \\
\hline Support and Services Contracts & Lazonick (2005); Etro (2009) \\
\hline In-House Private Clouds & $\begin{array}{l}\text { Schubert, Jeffery and Neidecker-Lutz (2010); Claburn (2009) } \\
\text { White papers: Oracle (2009 a; 2009 b); Sun Microsystems (2009); } \\
\text { Vmware (2010 a; 2010 b) } \\
\text { Note: Hull (2009) - supporting the same idea although he is based on } \\
\text { microeconomic points of views only. }\end{array}$ \\
\hline All-In-One Enterprise & $\begin{array}{l}\text { Lazonick (2005) } \\
\text { Weinhardt et al. (2009 a) }\end{array}$ \\
\hline One-Stop Resources and Services & $\begin{array}{l}\text { White paper: CSTransform (2009); } \\
\text { Jassen and Joha (2010); Kiu, Yuen and Tsui (2010) }\end{array}$ \\
\hline Government Funding & Lazonick (2005); Educause (2008) \\
\hline Venture Capital & Hunt et al. (2003); Lazonick (2005) \\
\hline Entertainment and Social Networking & $\begin{array}{l}\text { Madhavapeddy et al. (2010), Maranto and Barton (2010) } \\
\text { White paper: IBM (2008), RightScale (2010) }\end{array}$ \\
& $\begin{array}{l}\text { Popular products: Apple iPhone; iPad; TV; iPod nano and Facebook (where } \\
\text { the press has much more articles and updates than papers) }\end{array}$ \\
\hline
\end{tabular}

Table 1: Papers for Criteria of Business Model Classification

There were start-ups such as Parascale using the seventh model to secure their funding, and they adopted the first model by being an IaaS provider. They moved onto the second model to generate more revenues. The National Grid Service (NGS) has used the sixth model to secure funding, and their strategy is to adopt the fifth model by becoming the central point to provide IaaS cloud services for the UK academic community. Facebook has used multiple business models, the first, seventh and eighth model to assist their rapid user growth and business expansion.

Guy's and St Thomas' NHS Trust (GSTT) and Kings College London (KCL) spent their funding on infrastructure and resources to deliver a PaaS project. Knowing that outsourcing would cost more than they could afford financially with possibility in project time delays, they decided to use the third business model, "In-House Private Clouds", which matched to cost-saving, a characteristic of Cloud. They divided this project into several stages and tried to meet each target on time. In contrast, there was another NHS project with more resources and funding, and they opted for vendors providing the second and forth business models, "Support and Service Contract" and "Allin-One Enterprise Cloud".

\subsection{Cloud Challenges in business ConText}

Section 2 and 3 describe Cloud for business uses and propose the categorization of business models into eight types. Knowing the strengths and weaknesses is useful for stake-holders and investors to make the right decisions and business plans. The next step is to identify core elements for successful Cloud Computing business is crucial. In the literature review there are business models including

(a) Cloud Cube Model proposed by Jericho's Forum (2009);

(b) Pay as you go model demonstrated by major vendors such as Amazon EC2 and S3;

(c) Seven models proposed by Chou (2009);

(d) Cloud OSS Business Model 3.0 presented by Lawson (2009);

(e) Waterfall models proposed by Schubert, Jeffery and Neidecker-Lutz (2010);

(f) Linear Value Chain and Ecosystem Models proposed by Luhn and Jaekel (2009).

Each of these models has their own interpretation for core elements. However, they suffer from a lack of economic and finance literature reviews, which should be addressed and applied before implementing any Cloud 
Computing strategies. Based on various economic and finance reviews (Anderton, 2008; Waters, 2008; Hull, 2009), there are five elements essential for every successful business. They are high volumes or confidence levels in consumers (customers), investors, popularity (or adoption), market valuation, and innovation. An example is Facebook, which has achieved 400 million users in six years of operation, where consumers, investors, popularity, valuation and innovation have reached the maximum level compared to competitors and analysts' expectations. Similarly, iPhone storms the market and takes the same route as Facebook. However, there is a missing factor, "get the job done" (GTJD) factor, which concerns whether services from a particular service provider can get the client's problems resolved, and whether their solutions are fully relevant as the cloud service, and regards the impacts of the service on clients' organizations. This is essential since some service providers use alternative ways with less relevance to clouds, which are awarded less for the merits of cloud computing. GTJD also needs lowering risks. GTJD is rated based on case studies and peer reviews in the form of surveys and interviews. GTJD is also supported by leading Cloud researchers. Buyya et al $(2008,2009,2010)$ demonstrates how their challenges are met, and their SLA models have been useful in getting their jobs and requirements done. Foster et al. (2008) demonstrates how Scientific Workflows can be achieved and fulfill scientific challenges. Both leading research groups have supported GTJD as a core factor for cloud business success. Table 2 shows each of six factors, and their supporting papers and books.

\begin{tabular}{|l|l|}
\hline Success factors & Papers and books \\
\hline Consumers & $\begin{array}{l}\text { Anderton, 2008; Waters, 2008; } \\
\text { Hull, 2009 }\end{array}$ \\
\hline Investors & $\begin{array}{l}\text { Anderton, 2008; Waters, 2008; } \\
\text { Hull, 2009 }\end{array}$ \\
\hline Popularity & $\begin{array}{l}\text { Anderton, 2008; Waters, 2008; } \\
\text { Hull, 2009 }\end{array}$ \\
\hline Valuation & $\begin{array}{l}\text { Anderton, 2008; Waters, 2008; } \\
\text { Hull, 2009 }\end{array}$ \\
\hline Innovation & $\begin{array}{l}\text { Anderton, 2008; Waters, 2008; } \\
\text { Hull, 2009 }\end{array}$ \\
\hline $\begin{array}{l}\text { Get the job done } \\
\text { (GTJD) }\end{array}$ & $\begin{array}{l}\text { Buyya et al. (2008, 2009, 2010); } \\
\text { Foster et al. (2008) }\end{array}$ \\
\hline
\end{tabular}

Table 2: Six successful factors for cloud computing businesses
High level core elements for successful Cloud Computing businesses, identified and presented in Table 2, are designed for strategic levels and are useful for long-term sustainability. However, operational management has a different perspective of core successful elements, since there is a difference in terms of problems and challenges faced by strategic executives and operational staff. To address this, Hosono et al $(2009,2010)$ asserts there are two sets of six core elements for operational management and project management, defining how important elements or quality factors fit into their Non-Functional Requirement (NFR) for IT Services. Table 3 show quality factors for Business to Customers (B to C). Hosono et al $(2009,2010)$ also show quality factors for Business to Business (B to B) defining criteria that businesses will review while outsourcing to other service providers. Six factors from each table are presented, and their characteristics are provided along with additional information in both tables.

In reviewing these six factors, all of them are relevant to Cloud Computing except customizability. The rationale is as follows. Although modifying applications or platforms is desirable according to Honsono et al (2009; 2010), scalability is an important factor, for instance Cloud Services are scalable to allow users to demand different requirements on hardware and software specifications. In other words, hardware and software requirements can be changed numerous times without impacting the business or services, and such changes are flexible and instant. A new instance of a Cloud application can be scaled to a small project, or to a large project involving thousands of datasets and staff working on it. Therefore, Scalability is a more suitable term than Customizability. Reliability is replaced with computational accuracy because some SaaS systems require high levels of accuracy for computational results. As demonstrated by Agopyan et al. (2011) and Peng et al. (2011), financial Cloud applications can compute a high volume of trading and accuracy of results play an influential role on investors.

Hosono et al. (2009, 2010) et al. have presented two sets of six core elements, which are used for developing a pair of Hexagon Models, which are helpful to review any Cloud projects and identify strengths and weaknesses. The next section is to describe the pair of the Hexagon Model, where one set focuses on Business Model and another focuses on IT services. 


\begin{tabular}{|l|l|l|l|l|l|}
\hline $\begin{array}{l}\text { Non-Functional Requirements } \\
\text { (NFR) for IT adoption }\end{array}$ & \multicolumn{4}{l|l|}{ Quality Factor } \\
\hline Usability & cost & $\begin{array}{l}\text { reasonable } \\
\text { price }\end{array}$ & value & low cost & low expenses \\
\hline Performance & comfort & Refreshment & enjoyment & freedom & carefree \\
\hline Security & safety & $\begin{array}{l}\text { easy to } \\
\text { understand }\end{array}$ & fairness & Justice & kindness \\
\hline Readability & certainty & $\begin{array}{l}\text { certainty to } \\
\text { complete }\end{array}$ & $\begin{array}{l}\text { processing } \\
\text { certainty }\end{array}$ & $\begin{array}{l}\text { source } \\
\text { certainty }\end{array}$ & appropriateness \\
\hline Portability & easiness & Coziness & comfort & optimism & agility \\
\hline Customizability & uniqueness & $\begin{array}{l}\text { individual } \\
\text { identity }\end{array}$ & $\begin{array}{l}\text { uniqueness } \\
\text { of time }\end{array}$ & locality & originality \\
\hline
\end{tabular}

Table 3: Part of NFR - Quality factors for B to C (Hosono et al., 2009, 2010)

\section{The PAIR OF THE HeXAgon MOdELS}

Chang et al. (2010 c) describe the origin and case studies of the Hexagon Model, which can be used to review Cloud organizational performance and to identify strengths and weaknesses in relations to business model and development. Positions in these six elements reflect their relations to each other.

\subsection{The HeXagon Model With Business Model} FOCUS

The six elements are divided into three pairs: people (consumers and investors); business (popularity and valuation) and job done with job variance (get the job done, GTJD and innovation). Each pair is opposite to each other in the hexagon. Consumers and popularity are related, so that they are next to each other, presented in Figure 1.

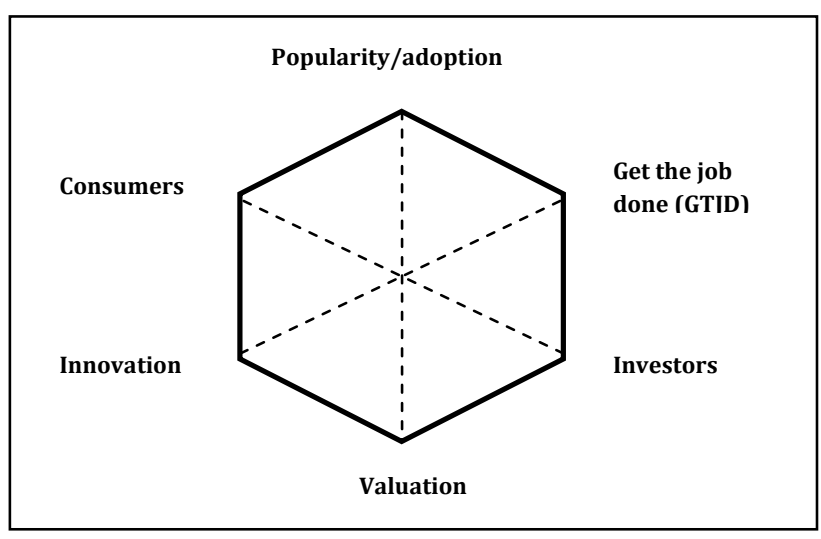

Figure 1: The Hexagon Model with Business Model focus

Being a popular service, ideally it should have GTJD factor helping client organization resolving its immediate needs with lowering risks. This in turn assists the service provider gaining trust and reputation, therefore, popularity and GTJD are next to each other. Investors are opposite to consumers, so investors are next to GTJD. Valuation is opposite to popularity, and is next to investors. The remaining element, innovation is then next to valuation and consumer respectively.

\subsection{The Hexagon Model With IT Service Focus}

Elements for the Hexagon Model (IT Service focus) are based on Hosono et al. (2009, 2010) work and these factors are useful to determine the extent of success for Cloud projects focusing on IT services.

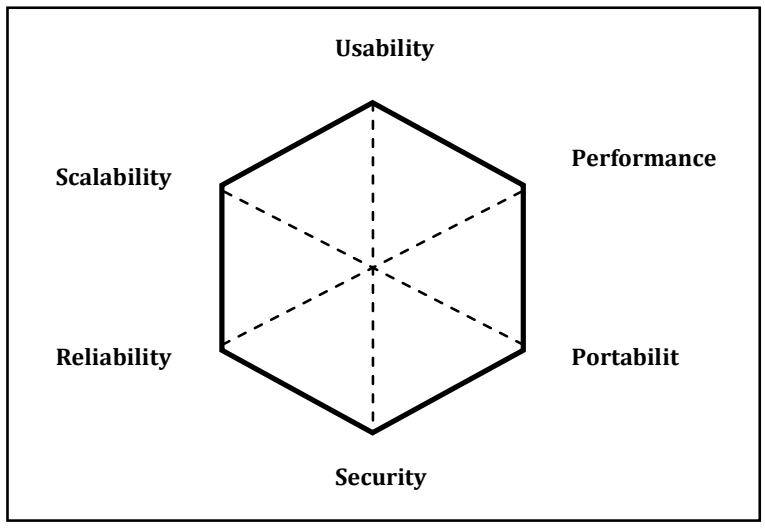

Figure 2: The Hexagon Model with IT Services focus

The rationale of positioning each element should be explained. The six elements can be divided into pairs: people and impact (usability and security); technical strength (performance and reliability) and desirable characteristics (portability and scalability). Though scalability is available in numerous cloud services, such a feature is not easily done on every service. Each pair is opposite to each other in the Hexagon. Usability is an essential part of IT Services, and is placed at the top. Security is paired up with Usability, since any security concerns and attacks are associated with human behaviours, and is thus opposite to Usability. Performance is an 
expectation of users, and is next to Usability. Reliability is paired up with Performance, which is opposite to it. Portability is a wanted feature so that users can move and transfer between desktops and Clouds apart from having good performance, and is thus next to Performance.

Scalability is paired up with Portability, which is opposite to it. In summary, Figure 2 is the representation.

\subsection{THE PAIR OF THE HEXAgON Models IS PART OF A}

\section{PROPOSED FRAMEWORK}

How the pair of the Hexagon Models is used for collaborators and Cloud services will be described at Section 12: Discussions of this paper. A proposed framework will be described at the later part of this paper to present how the pair of the Hexagon Models can be used for different Cloud services and to review their strengths and weaknesses. The framework approach can ensure there is a better management of resources and address issues and demands from organizational challenges as a result of Cloud adoption.

\section{Organizational Challenges for Cloud adoption}

Security and privacy are considered as technical challenges of Cloud adoption (Chang et al., $2011 \mathrm{c}$ ) and investigations from Chang (et al. 2011 a) presents a finedgrained model to ensure layers of security checks and technologies can ensure services are protected and safeguarded offline and in real-time. Organizational challenges arise while deploying Cloud adoption. Research objective needs to identify these challenges and proposes the appropriate research questions, which address issues on organizational challenges.

\subsection{THREE IDENTIFIED ORGANIZATIONAL CHALLENGES}

There are initiatives explaining Service Level Agreements (SLA) can demonstrate cloud business models (Brandic et al., 2009; Buyya et al., 2009). A drawback is they only focus on operational levels. To help organizations designing, deploying and supporting clouds, especially private clouds, using both strategic and operational approaches will be more favorable. Armbrust et al. (2009) described Cloud technical challenges, and considered vendors' lock-in, data privacy, security and interoperability as most important challenges. Security and privacy being areas that require regular improvement, there are other critical organizational challenges (Weinhardt et al., 2009).
There are three organizational challenges described as follows.

Firstly, all cloud economic models and frameworks proposed by leading researchers are either qualitative (Briscoe and Marinos, 2009; Chou, 2009; Weinhardt et al., 2009; Schubert, Jeffery and Neidecker-Lutz, 2010) or quantitative (Brandic et al., 2009; Buyya et al., 2009; Armbrust et al., 2009). Qualitative research focuses on defining the right strategies, business model classifications, business requirement collection and customer requirement supported by case studies and user feedback. Quantitative research focuses on billing and pay as you go models, Return on Investment (ROI) calculations and validation supported by experiments or simulations. Each model, either qualitative or quantitative, is self-contained. Each contains a series of proven hypotheses and methods supported by case studies and/or experimental results. Generally there is no interaction or collaborative work between different models and services. This means there is no connection between quantitative and qualitative-based Cloud services. However, this is essential for Linkage, as the business requirements collected by qualitative services need to transform to quantitative Cloud analysis. Traditionally, many organizations employ business analysts to bridge the gap between quantitative and qualitative services / requirements. When a business function needs both services but there is no method of using both together as a service. For example, there are services focusing on customer relationship and there are services focusing on risk analysis in organizations and both services are not connected. Hence, the first challenge is "No connections between different services".

Secondly, there is no accurate method for analyzing risk and return other than the stock market equivalent approach. A drawback with the stock market is that it is subject to accuracy and reliability issues (Chang et al., 2010 c; 2010 d). There are researchers focusing on business model classifications and justifications for why cloud business can be successful (Chou, 2009; Weinhardt et al., 2009). But these business model classifications need more cases to support them and more data modeling to validate them for sustainability. Ideally, a structured framework is required to review risk and return analysis and sustainability in systematic ways. "No structured measurement of Cloud risk and return analysis" is the second challenge. 


\begin{tabular}{|l|l|l|}
\hline Challenges & Research questions & Framework key areas \\
\hline $\begin{array}{l}\text { Do not have a structured } \\
\text { measurement of risk and } \\
\text { return analysis }\end{array}$ & $\begin{array}{l}\text { How do you measure cloud of } \\
\text { risk and return analysis } \\
\text { accurately? }\end{array}$ & $\begin{array}{l}\text { Organizational Sustainability: Measure risk and return } \\
\text { analysis, supported by eight case studies and each one has } \\
\text { a different ROI presented. }\end{array}$ \\
\hline Service portability & $\begin{array}{l}\text { How do you demonstrate } \\
\text { Cloud portability? }\end{array}$ & $\begin{array}{l}\text { Service portability: Deal with Cloud portability of all } \\
\text { types, supported by FSaaS. }\end{array}$ \\
\hline $\begin{array}{l}\text { No connections between } \\
\text { different services }\end{array}$ & $\begin{array}{l}\text { How do you link and integrate } \\
\text { different services? }\end{array}$ & $\begin{array}{l}\text { Linkage: Link and integrate different activities and } \\
\text { between different types of Cloud services. }\end{array}$ \\
\hline
\end{tabular}

Table 4: Relations between organizational challenges, research questions and framework key areas

Thirdly, communications between different types of clouds from different vendors are often difficult to implement. Often work-arounds require writing additional layers of APIs, or an interface or portal to allow communications. This brings interesting research question such as portability, as portability of some applications from desktop to cloud is challenging (Beaty et al., 2009; Armbrust et al., 2009). Portability refers to moving enterprise applications and services to Clouds from all types, and not just files or VM over clouds. Portability is the third challenge.
The rise of Cloud Computing brings technical and organizational challenges in many organizations. To address increasing requirements from Industry and Academia, a structured framework to provide business needs, recommend for the best practices and can be adapted in different domains and platforms is necessary. The framework aims to help adopting organizations to overcome organizational challenges. Table 4 presents the relations between organizational challenges, research questions and framework key areas.

\subsection{HOW THOSE CHALLENGES RELATE TO THIS RESEARCH}

\begin{tabular}{|l|l|l|}
\hline $\begin{array}{l}\text { Key areas } \\
\text { addressing } \\
\text { research } \\
\text { questions }\end{array}$ & Literatures & Remarks \\
\hline $\begin{array}{l}\text { Organizational } \\
\text { Sustainability }\end{array}$ & $\begin{array}{l}\text { Weinhardt et al. (2009) } \\
\text { Klems, Nimis and Tsai (2008) } \\
\text { Mohammed, Altmann and } \\
\text { Hwang (2010) }\end{array}$ & $\begin{array}{l}\text { Although all authors identify organizational sustainability as a challenge, } \\
\text { none of them has addressed any quantitative way of measurement. This is } \\
\text { related to Organizational Sustainability Modeling (OSM) and ROI, which } \\
\text { have to be done accurately. Section 9.1 and 11.1 describe a structured way } \\
\text { for investigation. }\end{array}$ \\
\hline $\begin{array}{l}\text { Service } \\
\text { Portability }\end{array}$ & $\begin{array}{l}\text { Ambrust et al. (2010) } \\
\text { Ahmend (2010) } \\
\text { Ahronovitz et al. (2010) } \\
\text { Friedman and West (2010) }\end{array}$ & $\begin{array}{l}\text { Often interoperability and portability are classified as one category. But } \\
\text { there are not many papers describing platform and application portability } \\
\text { over different clouds in detail. Case studies such as Finance application } \\
\text { portability should be encouraged. Portability needs to take performance, } \\
\text { accuracy and security into consideration. }\end{array}$ \\
\hline Linkage & $\begin{array}{l}\text { IBM SOA framework (2010) } \\
\text { Klems, Nimis and Tsai (2008) } \\
\text { Etro (2009) } \\
\text { Hosono et al. (2009) } \\
\text { Ring et al. (2009) } \\
\text { Moran et al (2011) } \\
\text { Papazoglou and van den } \\
\text { Heuvel (2011) }\end{array}$ & $\begin{array}{l}\text { Enterprise Service Bus (ESB) links between different aspects of business } \\
\text { processes but drawback is it needs a high level of complexity to define, } \\
\text { write and validate business processes. In addition, Klems, Nimis and Tsai } \\
\text { (2008) attempt for linkage but their framework is not yet completed. Etro } \\
\text { (2009) explain his linkage methodology for SME, but his approach is very } \\
\text { econometrics and is not entirely suitable for Cloud Computing. Part of } \\
\text { Hosono et al. (2009) have been adapted. See Section 9.3 and 11.3. } \\
\text { Business Integration as a Service (BIaaS) is proposed and demonstrated. }\end{array}$ \\
\hline
\end{tabular}

Table 5: The current status for three CCAF key areas (addressing research questions) 


\section{LITERATURES SUPPORTING THE PROPOSED FRAMEWORK, THE CLOUD COMPUTING ADOPTION FRAMEWORK (CCAF)}

Cloud Computing Adoption Framework (CCAF) is a dynamic framework to help organizations achieving good Cloud design, deployment, migration and services. Three areas to address research questions are identified for the CCAF, and they are (i) Organizational Sustainability, (ii) Portability and (iii) Linkage. A summary of the literature review, and identification of gaps and types of work that is not being done by others, is in Table 5 .

\section{FRAMEWORK APPROACH: THREE KEY AREAS TO ADDRESS RESEARCH QUESTIONS}

A good framework can accommodate multiple methods or solutions to work in different contexts and consolidate each towards the goal of the framework (Sander et al., 2004; Jiang et al., 2006). In an ideal situation, a framework should address each research question with a key area and offer methodology proving the validity. Each key area is described about the scope and types of services involved.

\subsection{ORGANIZATIONAL SUSTAINABILITY AND ITS ROLE TO CCAF DEVELOPMENT}

Organizational Sustainability in this research is about reviewing risk and return analysis. It includes risk and return analysis, based on the improvement of a Nobel-prize winning model, the Capital Asset Pricing Model, CAPM (Sharp, 1990). The improved model is a systematic and innovative methodology based on (i) the use of economic and statistical computation for data analysis; (ii) 3D Visualization to present risk and return analysis and finally (iii) offers a high extent of accuracy of $99.99 \%$ data quality and consistency to ensure Quality Assurance (QA) of data analysis and interpretations. This leads to the development of Organizational Sustainability Modeling (OSM) which is designed to measure risk and return analysis. Using OSM has the following two advantages: (i) it allows performance reviews at any time; and (ii) it provides strategic directions and added-values for adopting the right types of cloud business for sustainability.

There are extensive case studies to support SM. Data from Apple/Vodafone, NHS, SAP, Oracle, Salesforce,
VMware, HP, KCL, Universities of Southampton and Greenwich, and several Small and Medium Enterprises (SMEs) are presented and analyzed in the form of statistical computing and 3D Visualization. ROI results and discussions have proven to be valuable not only for publications but also for collaborators. Organizational Sustainability is not restricted to any domains.

\subsection{PoRTABILITY AND ITS ROLE TO CCAF DEVELOPMENT}

Portability involves moving applications and services from desktops to clouds and between different clouds in a way which is transparent to users so they may continue to work as if still using their familiar systems. This is important aspect as portability can be time consuming and not easy to be implemented. For financial services and organizations that have not yet adopted clouds, achieving this type of portability involves a lot of investment in terms of time and money, and is a challenge. Friedman and West (2010) classify portability as a business challenge and recommend three issues to be resolved: (i) Transparency; (ii) Competition and (iii) Legal Clarification. Nevertheless, work in portability requires modeling, simulations and experiments on different Clouds. A selection of domain is required due to the complexity and time involved. Finance domain is used for demonstration.

\subsection{LINKAGE AND ITS ROLE TO CCAF DEVELOPMENT}

There are three types of services: IaaS, PaaS and SaaS. A cloud project often has a particularly focus, and when the project develops over a period of time, factors such as customer requirements, business opportunities and evolvement from existing project may push the type of services upwards, such as upgrading from IaaS to PaaS. Three examples which illustrate this in the use of CCAF are the experiences of Guy's and St Thomas NHS Trust (GSTT), a Small and Medium Enterprise (SME) that does not wish to reveal its identity and MyExperiments.

Guy's and St Thomas NHS Trust (GSTT) have started a Private Cloud project (Cloud Storage) with King's College London (KCL) to build and consolidate infrastructure. With increasing research needs and user demands, it needs to upgrade to PaaS to provide three different services. The first service is 3D Bioinformatics to develop applications for 3D genes, proteins, DNA, tumor and brain images. The second service is Computational Statistics for researchers to write statistical applications and perform high performance calculations. The third service is the extended Cloud storage 
project that allows writing and improving applications and functionality. These three services have been successfully upgraded from IaaS to PaaS, and have satisfactory user feedback.

The second example is a participating Small and Medium Enterprise (SME) that does not wish to reveal its identity. This SME offers broadband, networking and telecommunication services, and has adopted virtualization for cost-saving. It has consolidated their infrastructure and moved from physical to virtual servers. Later, they had strong customer demands for storage, and fast video and music downloads, which makes them agile for changes. This SME has developed in-house applications and thirdparty tools with their business partners to allow their customers to archive files on their storage and also to have a faster downloads of video and music. It is a good example of upgrading services from IaaS to PaaS.

The third example is myExperiment project (De Roure et al., 2010). MyExperiment was initially used as a PaaS to allow researchers to publish and share their data, whether in the public domain or users' own domains. It has developed into a SaaS to meet increasing demands, and to allow other researchers to extract research analysis and results allowing research collaboration in virtual and cloud environments.

Linkage between different types of services is required, and is dependent on factors such as business needs, user demands and further development from existing problems. A structured method should also be easy to understand and use to review risk and return analysis at any time. Part of the Linkage can connect both qualitative and quantitative research methods and services.

\section{HOW DIFFERENT KEY AREAS FIT INTO CCAF ALTOGETHER}

A framework is the most suitable approach to sum up all different areas and present them as a single, hybrid conceptual solution. All different areas to address research questions can be tied up and integrated within the same framework. Therefore, the proposal of the CCAF is in place, where CCAF includes all the work from each key area can be performed independently and collaboratively with other areas. How different key areas fit into CCAF can be explained in the following paragraph.
Each CCAF key area corresponds to each research question. CCAF has three key areas and how each area fits to the architectural layout is explained as follows.

1. Organizational Sustainability: This applies to any businesses and organizations adopting Cloud and is applicable to IaaS, PaaS and SaaS layers.

2. Portability: Same as Organizational Sustainability but is domain specific. Finance is the chosen domain for demonstration.

3. Linkage: It connects different Cloud methods and services together and its position is between different layers to connect different research areas altogether.

The CCAF has the advantage over Weinhardt et al. (2009 a; 2009 b) framework because of the following three reasons. Firstly, it provides both upward and downward directions in each layer. This allows any organizations to transform from one type of businesses to another, and upgrade of services from IaaS to PaaS and SaaS is flexible. Downward directions show the dependability of each layer if service upgrades have happened. It also means any business strategies and requirements, can pass on from strategic level to operational level. Secondly, the research questions are closely related to the model, and there are data and experiments with collaborators to validate. Thirdly, it provides linkages between layers of IaaS, PaaS, SaaS and Business Models within the CCAF, and between CCAF and other methods.

The CCAF also focuses on conceptual and architectural frameworks and it allows a series of conceptual methodologies to apply and fit into Cloud Architecture and Business Models. It allows integrations of two completely different services to demonstrate Linkage.

\section{Research Contributions AND BENEFITS FOR COLLABORATORS OFFERED BY CCAF}

Each CCAF key area has its own merit of research contributions and benefits for collaborators. With the support from case studies, they can be summed up in each sub-section.

\subsection{RESEARCH CONTRIBUTIONS OFFERED BY ORGANIZATIONAL SUSTAINABILITY \\ Organizational Sustainability in this research is about reviewing risk and return analysis. It includes Return on Investment (ROI) measurement, which is a systematic and}


innovative methodology based on (i) Nobel-prize models such as the Capital Asset Pricing Models, CAPM (Sharp, 1990); (ii) the use of economic and statistical computation for data analysis; (iii) 3D Visualization to present risk and return analysis and finally (iv) a unique way to use Quality Assurance (QA) to improve the quality of data and research outputs. This leads to the development of Organizational Sustainability Modeling (OSM) which is designed to measure risk and return analysis. Using OSM has the following two advantages: (i) it allows performance reviews at any time; and (ii) it provides strategic directions and added-values for adopting the right types of cloud business for sustainability.

There are extensive case studies to support OSM. Data from Apple/Vodafone, NHS, SAP, Oracle, Salesforce, VMware, HP, KCL, Universities of Southampton and Greenwich, and several a Small and Medium Enterprise (SME) are presented and analyzed in the form of statistical computing and 3D Visualization. ROI results and discussions have proven to be valuable not only for publications but also for collaborators. Organizational Sustainability is not restricted to any domains.

- X-axis: Vodafone's return (21-24\%)

- $y$-axis presents risk premium of the market return (22-26\%)

- $\mathrm{z}$-axis presents risk-free rate in market (2.0-4.0\%)

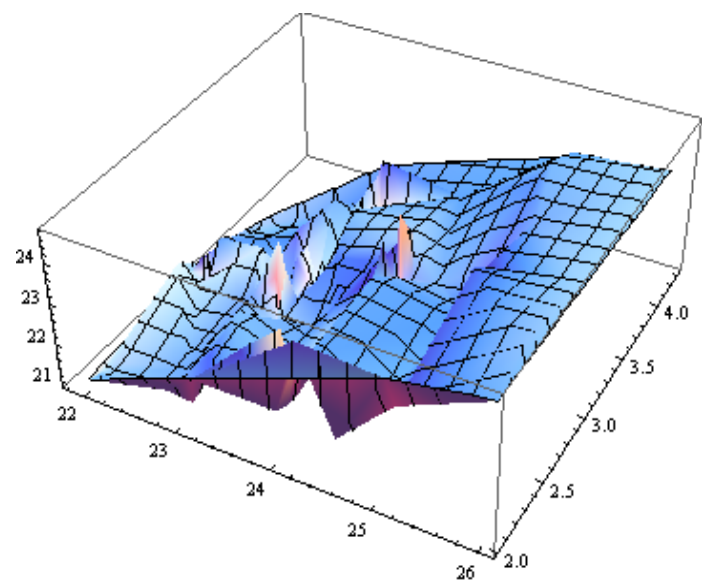

Figure 3: 3D Visualization for Vodafone with iPhone and iPad strategies

Figure 3 shows 3D Visualization for Vodafone/Apple Cloud risk and return analysis when Vodafone adopted iPhone and iPad strategies to boost their revenues, where they received additional profits between 21 to $24 \%$ and has risk premium of the market return between 22 to $26 \%$.
Chang et al. (2011 c) have demonstrated how statistical analysis can be computed in 3D Visualization. The benefits include:

- There is no need to analyze more data from statistical analysis. Often statistical computation leads to more data to analyze.

- 3D analysis can be understood and interpreted easily and is particularly useful for stake-holders who may not have economic and finance backgrounds.

\subsection{RESEARCH CONTRIBUTIONS OFFERED BY \\ PORTABILITY}

Portability involves moving applications and services to clouds from desktops to clouds and between different clouds in a way which is transparent to users so they may continue to work as if still using their familiar systems. This is important aspect as portability can be time consuming and not easy to be implemented. For financial services and organizations that have not yet adopted clouds, achieving this type of portability involves a lot of investment in terms of time and money, and is a challenge. Friedman and West (2010) classify portability as a business challenge and recommend three issues to be resolved: (i) Transparency; (ii) Competition and (iii) Legal Clarification. Nevertheless, work in portability requires modeling, simulations and experiments on different Clouds. Financial Software as a Service (FSaaS) is demonstrated which uses Monte Carlo Methods (MCM) and 3D black Scholes Model (BSM) to quantify and visualize risks. Cloud portability in Finance and can be presented in terms of how CCAF gets involved as follows.

- CCAF helps different types and requirements for Portability. Various demonstrations support that Finance portability is an important organizational agenda and meet organizational challenges including the architecture for private cloud development.

- Portability uses execution time for performance benchmarking. Portability uses simulations, modeling, experiments and hybrid case studies as research methods.

Figure 4 shows simulations of a company affected by Year 2008 financial crisis and shows the percentage of loss gets better when the put prices are raised to approximately 55. However, when it gets to 60 , this is the price that uncontrolled volatility (such as human speculation or natural disasters) takes hold and the percentage of loss goes down sharply at $-25 \%$. 
$\mathrm{x}$-axis: The best put price $(20-100)$

$y$-axis: The percentage of loss $(-5$ and $-25 \%)$

$\mathrm{z}$-axis: the risk-free rate $(0-0.5 \%)$

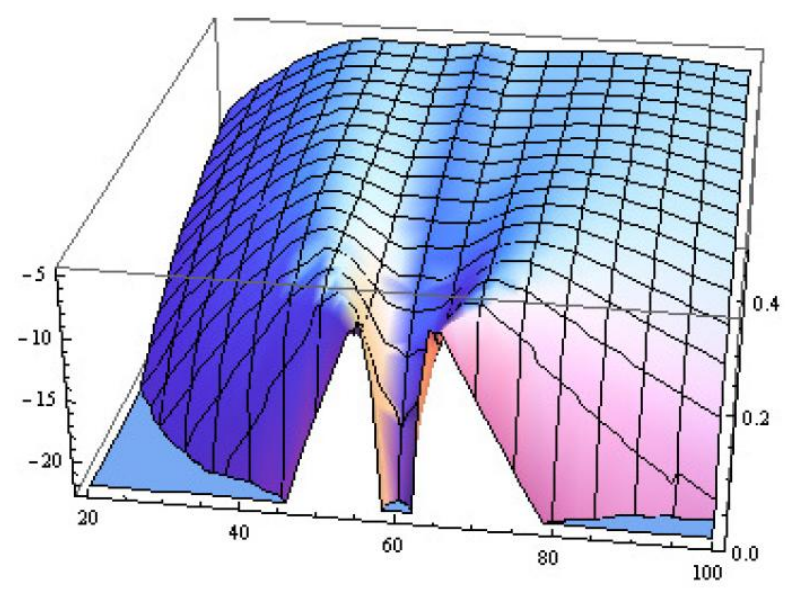

Figure 4: The 3D risk analysis to explore the percentage of loss and the best put price in relations to the impact of economic downturn

\subsection{RESEARCH CONTRIBUTIONS OFFERED BY BUSINESS}

\section{INTEGRATION AS A SERVICE}

Integration between different types of services is required and all services need to be carried out within the same framework without communications and technological barriers (such as BPEL to BPMN). This motivates us to propose and demonstrate Business Integration as a Service (BIaaS), which is a way to demonstrate Linkage and aims to offer the following:

- To allow two or more different services to work together where traditionally each service would be separate from the others.

- To permit the outcome of one service to be used as input for another; integrating two or more services into one.

This motivates us to propose and demonstrate Business Integration as a Service (BIaS), which is a way to demonstrate Linkage and aims to offer the following:

- To allow two or more different services to work together where traditionally each service would be separate from the others.

- To permit the outcome of one service to be used as input for another; integrating two or more services into one.

Chang et al. (2012 a) demonstrate two different case studies for University of Southampton and Vodafone/Apple to demonstrate how two different services can work together as a as single service. Service 1 is RMaaS which includes three steps. It requires completion of at least the first two steps before presenting results. Each step in RMaaS is considered as a sub-service as follows:

1. Statistical service: This computes Cloud risk and return analysis with key statistical data offered by SAS, a statistical program.

2. Visualization service: Results from statistical service pass onto this step which presents key data using 3D Visualization enabled by Mathematica. Completion of this step is the minimum requirement for RMaaS.

3. Quality Assurance service: This is an additional step required when connecting to another service. It ensures data quality and performs further analysis of the implications of data.

Results are saved in text formats readable by each service and then passed onto the next step. Service 2 is RAaaS which is itself comprised of two steps. Results from the last step of RMaaS are passed onto the first step of RAaaS. Similar to RMaaS, each step in RAaaS is a subservice and the two steps are:

1. Variance-Gamma Process (VGP) risk analysis service: This reduces inconsistencies and errors and calculates the risk pricing. It computes results showing frequency of occurrence and risk pricing.

2. Least Square Method (LSM) risk analysis service: This computes high-performing simulations and calculates the most likely risk pricing and its upper and lower bounds. Integrating RMaaS and RAaaS requires the following:

- Results from the end of RAaaS and the end of each step need to be saved as text and passed to the next step, allowing results from each service to be passed onto the next.

- Use requests (ROI measurement and risk analysis) are completed in one rather than as two separate services.
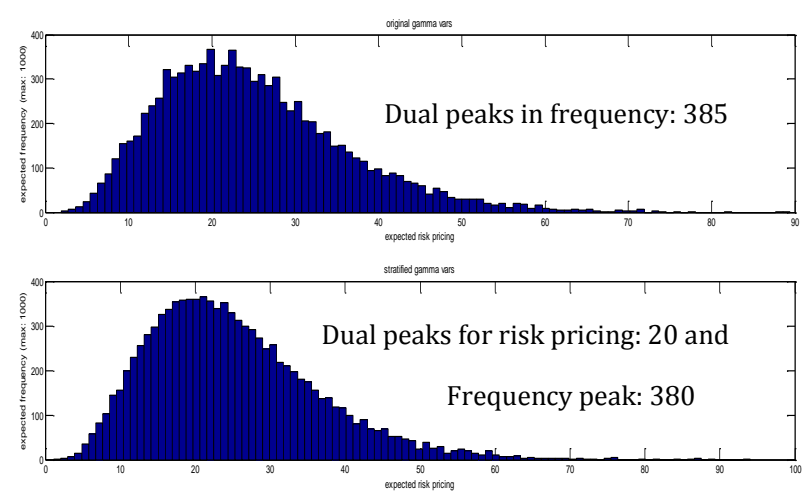

Risk pricing peak: 21 
Figure 5: Error correction by VGP: Risk pricing and frequency of occurrence for Vodafone/Apple strategy

Figure 5 shows VGP risk analysis service for Vodafone/Apple to reduce errors and calculate the risk pricing. After the VGP corrections, peak risk pricing is 21 with the frequency peak of 380 out of 1000 . This ensures a high level of accuracy can be achieved for risk analysis.

Chang et al (2011 a; 2012 a) explain the code algorithm for their LSM risk analysis service and the calculation for both American and European options are presented as:

$$
\begin{aligned}
& \text { MCAmericanPrice }=23.8412 \\
& \text { MCEuropeanPrice }=21.1682
\end{aligned}
$$

Chang et al (2011 a; 2012 a) continue to use LSM risk analysis service as a precision method to calculate the most accurate American and European prices. In their case study, they demonstrate how RMaaS and RAaaS services can work together. This allows analysis from ROI measurement to connect to risk analysis and to produce the combined results to an organization which needs to understand their ROI and risk in quantitative representation. In summary, BIaaS is one of the first demonstrations for Cloud services to allow different services to work together as a service. Chang et al (2012 a) confirm such demonstration offers the following benefits:

- This data is useful for University of Southampton management board. This case study demonstrates RMaaS and RAaaS can be integrated and key data is useful for University management.

- Vodafone/Apple case study demonstrates RMaaS and RAaaS can be integrated and key data is useful for current and potential investors.

\section{Discussions}

There are two major topics for discussion. The first topic is the use of Hexagon Models to evaluate and review the extents of success for Cloud services.

\subsection{CLOUd SERVICES REVIEWED BY THE PAIR OF THE HEXAGON ModeLS}

There are two Cloud services that have been actively used and adopted by two different communities. The first service is Healthcare Platform as a Service (HPaaS) designed and implemented for National Health Service (NHS) UK based at Guy's and St Thomas NHS Trust and King's College London to provide daily backup, data storage and automation services. The second service is Financial Software as a Service (FSaaS) designed, built and led by University of Southampton which collaborate with IBM US and Commonwealth Bank Australia (CBA). The pair of the Hexagon Model is used to evaluate the extent of success for both services.

\subsection{THE HEXAGON MODEL (BUSINESS MODEL): REVIEW FOR HPAAS (CLOUD STORAGE)}

Cloud Storage is seen as the most successful HPaaS Cloud service as some users rely on its backup and archiving services on a daily basis, including automated and easy-to-use back up of all experimental results, tumor and cancer images, publication and computational analysis. Cloud Storage is reviewed by a pair of Hexagon Models, one focuses on Business Model and the other focuses on IT services.

Figure 6 shows the Hexagon Model (Business Model), where Innovation is seen as the highest score, followed by GTJD and consumers. That is because Cloud Storage offers a collaborative platform to meet user and executive requirements and demonstrate how to design, build and migrate to a new platform and services which meet technical and business challenges. There is a good satisfaction rate from consumers since they are happy that Cloud Storage makes their research work easier than before the implementation and need not worry about complexity of backing up different analysis and images for different groups.

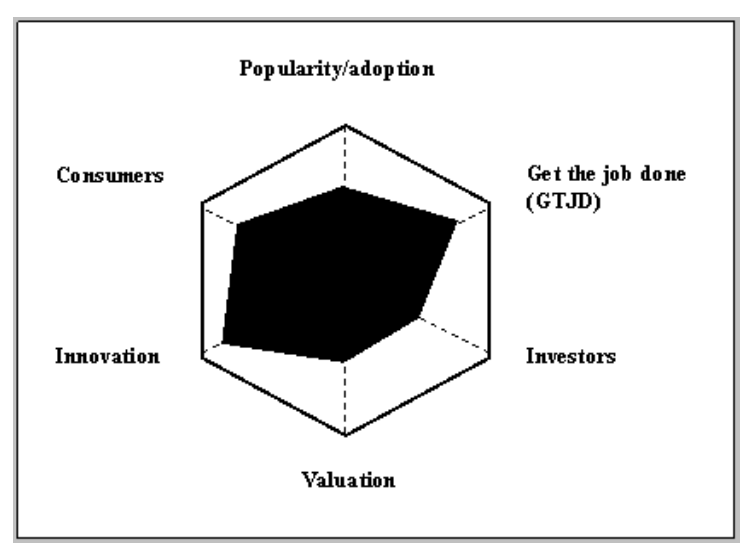

Figure 6: The Hexagon Model (Business Model) for HPaaS (Cloud Storage)

Its valuation and popularity has mid-range scores since only one NHS Trust is keen to maintain this service and it does not appeal to other NHS Trusts yet due to funding and 
organizational issues. The lowest score is in Investors as they make it clear there is no more funding or very little funding to sustain this service.

\subsection{THE HEXAGON MODEL (IT SERVICES) REVIEW FOR HPAAS (CLOUD STORAGE)}

Figure 7 is the Hexagon Model (IT Services) for Cloud Storage, where Scalability and Portability are seen as the highest score because it is designed and built for the objective of enterprise portability and has been tested to be scaled up from $20 \mathrm{~TB}$ to $44 \mathrm{~TB}$ without service interruptions.

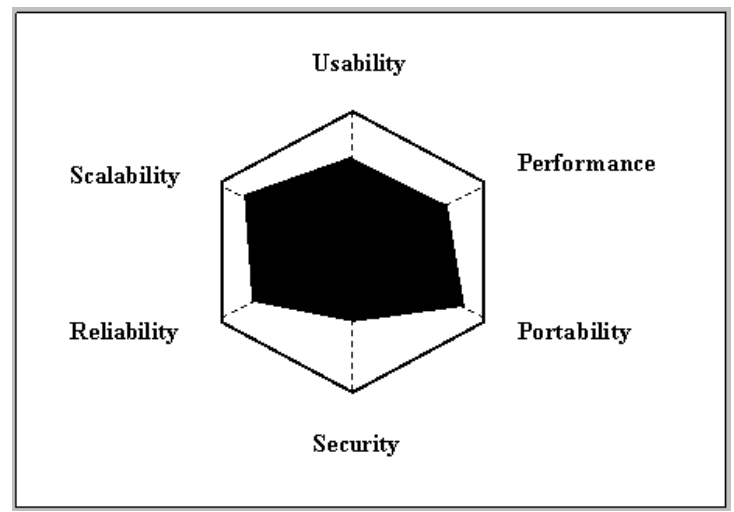

Figure 7: The Hexagon Model (IT Services) for HPaaS (Cloud Storage)

The Architecture provides good flexibility to upgrade and to migrate data, images and experimental analysis between different Clouds. This also causes performance and reliability to have a high score, where service delivery time meets users' high expectations, and relative performance between Cloud Storage and old services (traditional storage) shows it has a much better performance in recovery and migration of data. Service downtime is infrequent, and if it happens, service availability is restored within minutes since there is another team with $24 / 7$ services. Usability is slightly lower than the performance score since it still involves a certain extent of system administration activities for advanced users or local administrators. Other than that, majority of users are happy with usability and services. Security is lowest not because of its lack of implementation. The hosted solution is based at the University of London network where they need to provide certain levels of privileges and network administrator rights to some collaborators. To support this, Chang et al. (2016 a) have use Organizational Sustainability Modeling (OSM) to measure user satisfaction and have reported the effectiveness of understanding usability and user feedback to improve the quality of content and services.

\subsection{Security and Privacy}

Security and privacy play important role to determine whether organizations will adopt Cloud Computing and the scale of adoption to be deployed. Due to ongoing online threats, data leakage, unauthorized access and hacking, privacy remains the number one factor for all types of Cloud security (Chang et al., 2016 b). Additionally, Chang et al. (2016 b) have conducted a large scale surveys from 400 professionals and more than $50 \%$ of companies that will spend more than $£ 1$ million for improving secure services between Year 2016 and 2019. To demonstrate the importance of Cloud security, Chang and Ramachandran (2016) and Chang et al. (2016 c) develop a multi-layered security in their Cloud Computing Adoption Framework (CCAF). They have implemented three types of security: firewall with access control; identity management and encryption. They have performed large scale penetration testing and ethical hacking to test their robustness of the system. They also use BPMN simulations to identify that all recovery and remedy actions should be completed within 125 hours in order to rescue Data Centre from being fully compromised. They have demonstrated the effective multilayered security can block and kill more than $99 \%$ of 2013 viruses and trojans which have been constantly injected into the multi-layered defense. Security and privacy remain important factors for Cloud computing adoption for growing number of organizations.

\section{Conclusion ANd Future Work}

This paper presents a review related to Cloud Computing focusing on the benefits of adoption and back ground to Cloud Business Model. This is highly relevant to industry and academia as there are growing numbers of organizations considering or adopting or actively using Cloud. Understanding Cloud usage and adoption in business context is highly relevant, where categorization of eight business models is presented with their strengths and weaknesses in place. Core elements for Cloud business are discussed and the pair of Hexagon Models is used to review project performance against their success factors. One set focuses on Business Model and factors include popularity, get-the-job-done (GTJD), investors, valuation, innovation and consumers. Another set focuses on IT Services and factors include performance, portability, reliability, security and scalability and usability. There are two services 
completed and managed by CCAF: HPaaS (Cloud Storage) and FSaaS which are reviewed and presented by the pair of the Hexagon Models. Scores against each success factor are presented and their rationales are explained and supported.

Cloud adoption leads to the organizational challenges where three challenges are identified. The research questions are addressed to deal with these issues. The use of a framework can help to manage Cloud design, deployment and services much better. As a result, CCAF is proposed where three key areas are identified to deal with three organizational challenges as follows.

- Organizational Sustainability: Measure risk and return analysis, supported by eight case studies and each one has a different ROI presented.

- Portability: Deal with Cloud portability of all types, supported by FSaaS.

- Linkage: Link and integrate different activities and between different types of Cloud services.

These three areas are supported by literatures and their roles to CCAF development have been explained in details. Organizational Sustainability uses CAPM to compute ROI and then transforms analysis into 3D Visualization. Portability focuses on migrating services and applications to Clouds from all types and how to use and manage Cloud services. Linkage is a method to use one type of services/methods and then have the ability to use other services/methods and is demonstrated by BIaaS to connect and integrate two different services.

Research contributions of CCAF are confirmed by each key area. They are supported by case studies. Organizational Sustainability presents complex data analysis in 3D Visualization to allow those without backgrounds to understand easily. Portability can simulate complex financial applications and calculate risks for Cloud adoption or investment such as simulations of 2008 financial crisis.

BIaaS demonstrates how RMaaS (related to Organizational Sustainability) and RAaaS (related to Portability) can work together as a single service. This improves efficiency, enhances quality of analysis and reduces costs. How CCAF can be used by organizations is explained and supported by use cases.

Business requirements and complexity in handling organizational challenges due to Cloud adoption need a structured and well-organized framework to deal with emerging issues and provide solutions for others. CCAF is a dynamic framework to help different types of Cloud services, whether ROI measurement, or portability to Cloud, or Risk Analysis or integrations of different services supported by implementations, case studies and publication.

CCAF has been extensively used in several organizations such as NHS UK, KCL, Universities of Greenwich, Southampton, Oxford, VMware, Vodafone/Apple, IBM, Commonwealth Bank Australia (CBA) and so on. Some collaborators find it useful for their organizations and contributions from CCAF can positively impact e-Research, Cloud, Grid, Healthcare, Finance, Education and Information Systems Communities.

\section{REFERENCES}

Anstett, T., Leymann F, Mietzner, R. and Strauch, S. (2009). Towards BPEL in the Cloud: Exploiting Different Delivery Models for the Execution of Business Processes, 2009 World Congress on Services, I, 610 July, Los Angeles, CA, USA.

Antonova, A. and Nikolov, R. (2009). Conceptual Framework of Innovative KMS Design within the Perspectives of Enterprise 2.0 and Cloud Computing, Proceedings of International Conference on Software, Services and Semantic Technologies, October 28-29, Sofia, Bulgaria, ISBN 978-954-9526-62-2.

de Assunção, M. D., di Costanzo, A., \& Buyya, R. (2010). A cost-benefit analysis of using cloud computing to extend the capacity of clusters. Cluster Computing, 13(3), 335-347.

Beaty, K., Kochut, A. and Shaikh, H. (2009). Desktop to Cloud Transformation Planning, "2009 IEEE International Symposium on Parallel and Distributed Processing”, May 23-May 29, Rome, Italy.

Biermann, E. and Ermel, C. (2009). Transforming BPMN to BPEL with EMF Tiger, IEEE International Conference on Web Services, July 6-10, Los Angeles, USA.

Brandic, I., Music, D., Leitner, P. and Dustdar, S. (2009). VieSLAF Framework: Enabling Adaptive and Versatile SLA-Management, the 6th International Workshop on Grid Economics and Business Models 2009 (Gecon09), 25- 28 August, Delft, The Netherlands.

Briscoe, G. and Marinos, A. (2009), Digital ecosystems in the clouds: towards community cloud computing", the 3rd IEEE International Conference on Digital Ecosystems and Technologies, June 1-3, New York, USA, pp. 103-108.

Buyya, R, Yeo, C. S. and Venugopal, S. (2008), Market-Oriented Cloud Computing: Vision, Hype, and Reality for Delivering IT Services as Computing Utilities, 10th IEEE International Conference on High Performance Computing and Communications, 2008 (pp. 5-13).

Buyya, R, Ye,o C. S., Venugopal, S., Broberg, J. and Brandic, I. (2009), Cloud computing and emerging IT platforms: Vision, hype, and reality for delivering computing as the 5th utility, Journal of Future Generation Computer Systems, Volume 25, Issue 6, June, Pages 559-616. 
Chen, X., Wills, G. B., Gilbert, L., Bacigalupo, D. (2010), Using Cloud for Research: A Technical Review, TesciRes Report for JISC, June.

Chang V, Mills, H and Newhouse (2007), S From Open Source to longterm sustainability: Review of Business Models and Case studies, UK eScience All Hands Meeting, Nottingham, UK, September.

Chang V, Bacigalupo D., Wills G., Roure D D. (2010 a), A Categorisation of Cloud Computing Business Models, poster paper, CCGrid 2010 IEEE conference, Melbourne, Australia, May.

Chang, V., Wills G, De Roure D (2010 b), A Review of Cloud Business Models and Sustainability”, IEEE Cloud 2010, the third International Conference on Cloud Computing, 5-10 July, Miami, Florida, USA.

Chang, V., Wills G. and De Roure D (2010 c) Cloud Business Models and Sustainability: Impacts for businesses and e-Research. In: UK e-Science All Hands Meeting 2010, Software Sustainability Workshop, 13-16th September, Cardiff.

Chang, V., Wills G, De Roure, D. and Chee, C. (2010 d), Investigating the Cloud Computing Adoption Framework - Modelling and Benchmarking of Financial Assets and job submissions in Clouds, the UK e-Science All Hands Meeting 2010, Research Clouds: Hype or Reality Workshop, 1316th September, Cardiff.

Chang, V., Li, C. S., De Roure, D., Wills, G., Walters, R. J. and Chee, C. (2011 a) The Financial Clouds Review. International Journal of Cloud Applications and Computing, 1 (2). pp. 41-63. ISSN 2156-1834, eISSN 2156-1826.

Chang, V, De Roure, D., Wills, G. and Walters, R (2011 b), Organisational Sustainability Modelling for Return on Investment: Case Studies presented by a National Health Service (NHS) Trust UK. Journal of Computing and Information Technology, 19 (2). ISSN Print ISSN 1330-1136 | Online ISSN 1846-3908.

Chang, V. (2014). A proposed model to analyse risk and return for Cloud adoption. Lambert Academic Publishing.

Chang, V., \& Ramachandran, M. (2016). Towards achieving Data Security with the Cloud Computing Adoption Framework, IEEE Transactions on Services Computing, 9(1), 138-151.

Chang, V., Walters, R. J., \& Wills, G. B. (2016 a). Organisational sustainability modelling-An emerging service and analytics model for evaluating Cloud Computing adoption with two case studies. International Journal of Information Management, 36(1), 167-179.

Chang, V., Ramachandran, M., Yao, Y., Kuo, Y. H., \& Li, C. S. (2016 b). A resiliency framework for an enterprise cloud. International Journal of Information Management, 36(1), 155-166.

Chang, V., Kuo, Y. H., \& Ramachandran, M. (2016 c). Cloud computing adoption framework: A security framework for business clouds. Future Generation Computer Systems, 57, 24-41.

Chou T (2009), Seven Clear Business Models, Active Book Press.

City A.M Newspaper (2010), available on http://www.cityam.com, accessed on April 16, 2014.
Denaro, G., Pezzè, M. and Tosi, D. (2009), Ensuring Interoperable Serviceoriented Systems through Engineered Self-Healing, the 7th joint meeting of the European software engineering conference and the ACM SIGSOFT symposium on The foundations of software engineering, 26-28 August, 2009, Amsterdam, The Netherlands.

Etro F (2009), The Economic Impact of Cloud Computing on Business Creation, Employment and Output in Europe, Journal of Review of Business and Economics, 54(2), 179-208.

Fischer, M. (2010), Compliant Access Management at BearingPoint with SAP BusinessObjects Access Control, Munich Cloud 2010, European Identity Conference, 4-7 May, Munich, Germany.

Foster, I., Zhao, Y., Raicu, I., Lu, S. Y. (2008), Cloud Computing and Grid Computing 360-Degree Compared", IEEE Grid Computing Environments (GCE08), 12-16 Nov, Austin, Texas, USA.

Giunta G, Laccetti G and Montella R (2008), Five dimension environmental data resource brokering on computational grids and scientific clouds, 3rd IEEE Asia-Pacific Services Computing Conference, 9-12 Dec, Yilan, Taiwan.

Haynie, M. (2009), Enterprise cloud services: Deriving business value from Cloud Computing, Micro Focus, 56-61.

Hignite, K., Katz, R. N. and Yanosky, R. (2010). Shaping the Higher Education Cloud, An EDUCAUSE and NACUBO White Paper, May.

Hobona, G., Fairbairn, D. and James, P. (2010), Orchestration of GridEnabled Geospatial Web Services in Geoscientific Workflows, IEEE Transactions on Automation Science and Engineering, page 407-411, Volume 7, No. 2, April.

Hosono, S., Kuno, A., Hasegawa, M., Hara, T., Shimomura, Y. and Arai, T. (2009). A Framework of Co-creating Business Values for IT Services, 2009 IEEE International Conference on Cloud Computing, September 2125, Bangalore, India.

Hull, J. C. (2009). Options, Futures, and Other Derivatives, Seventh Edition, Pearson, Prentice Hall, 2009.

Hwang, K., Kulkarni, S. and Hu, Y. (2009). Cloud Security with Virtualized Defense and Reputation-based Trust Management, 2009 Eighth IEEE International Conference on Dependable, Autonomic and Secure Computing, 12-14 December, Chengdu, China.

Jiang, T. J., Liu, D., Liu, K. M., Yang, W. Z., Tan, P. T., Hsieh, M. J., Chang, T. H., Hsu, W. L. (2006), OpenVanilla - A Non-Intrusive Plug-In Framework of Text Services, ACM Journal, Computing Research Repository.

Kangasharju, J., Lindholm, T. and Tarkoma, S. (2008). XML Security with Binary XML for Mobile Web Services", International Journal of Web Services Research, page 1-19, Volume 5, number 3, July- September.

Klems, M., Nimis, J. and Tai, S. (2009). Do Cloud Compute? A Framework for Estimating the Value of Cloud Computing, Journal of Designing E-Business Systems - Market, Services and Network, Volume 22, Part 4, 110-123.

Lobo, L. O. and Arthur, J. D. (2005), An Objectives-Driven Process for Selecting Methods to Support Requirements Engineering Activities, 29th Annual IEEE / NASA Software Engineering Workshop, 6-7, Greenbelt, Maryland, USA. 
Lu, W., Jackson, J., \& Barga, R. (2010, June). AzureBlast: a case study of developing science applications on the cloud. In Proceedings of the 19th ACM International Symposium on High Performance Distributed Computing (pp. 413-420).

Luhn, A. and Jaekel, M. (2009), Cloud Computing - Business Models, Value Creation Dynamics and Advantages for Customers", Siemens White Paper.

Martino, L. D. and Bertino, E. (2009), Security for Web Services: Standards and Research Issues, International Journal of Web Services Research, page 48-74, Volume 6, Number 4, October-December.

Mastropietro, L. (2010). Managed IAM Service Project at Piaggio, Munich Cloud 2010, European Identity Conference, 4-7 May, Munich, Germany.

O'Reilly, T. (2007), What Is Web 2.0: Design Patterns and Business Models for the Next Generation of Software, Munich Personal RePEc Archive (MPRA) Paper No 4578, November.

Paci, F., Bertino, E. and Crampton, J. (2008). An Access-Control Framework for WS-BPEL, International Journal of Web Services Research, 5(3), pp 20-43, July- September.

Pajorova, E. and Hluchy, L. (2010). 3D visualization the results of complicated Grid and Cloud-based applications, the 14th International Conference on Intelligent Engineering Systems (INES), 5-7 May, Las Palmas, Spain.

Pearson, S. and Charlesworth, A. (2009). Accountability as a Way Forward for Privacy Protection in the Cloud, HP Laboratory, Technical Paper.

Prechter, R. R. Jr and Parker, W. D. (2007), The Financial and Economic Dichotomy in Social Behavioral Dynamics: the Socionomic Perspective, the Journal of Behavioural Finance, page 84-108, Vol. 8, No. 2.

Raafat, H. M. N. (1989), Risk Assessment and Machinery safety, Journal of Occupational Accidents, page 37-50.

Sanders, W. H., Courtney T, Deavours D, Daly D, Derisavi S and Lam V (2004), Multi-Formalism and Multi-Solution-Method Modelling Frameworks: The Mobius Approach. In Proceedings of the Symposium on Performance Evaluation, 2004.

Schubert, L., Jeffery K and Neidecker-Lutz B (2010), The Future for Cloud Computing: Opportunities for European Cloud Computing Beyond 2010, Expert Group report, public version 1.0, January.

Sloman, M. (2001), The e-learning Revolution: From Propositions to Action, CIPD, ISBN: 0852928734.

Sobel, W., Subramanyam, S., Sucharitakul, A., Nguyen, J., Wong, H., Klepchukov, A., Patil, S., Fox, A., Patterson, D. (2008), Cloudstone: MultiPlatform, Multi-Language Benchmark and Measurement Tools for Web 2.0, In Proceeding of Cloud Computing and its Applications (CCA 2008), 22-23 October, Chicago, USA.

Sun, Y.L., Perrott, R., Harmer, T., Cunningham, C., Wright, P., Kennedy, J., Edmonds, A., Bayon, V., Maza, J., Berginc, G., Hadalinz, P. (2009), SLA-Aware Resource Management, Service Level Agreements in Grids Workshop, October 13, Banff, Canada.

Tsalgatidou, A., Athanasopoulos, G. and Pantazoglou, M. (2008), Interoperability Among Heterogeneous Services: The Case of Integration of P2P Services with Web Services, International Journal of Web Services Research, 5(4), pp 79-110, October-December.
Vouk, M. A. (2008). Cloud Computing - Issues, Research and Implementations, Journal of Computing and Information Technology - CIT 16, page 235-246, Volume 4.

Yee, G. O.M. and Korba, L. (2008). Security Personalization for Internet and Web Services", International Journal of Web Services Research, page 1-22, Volume 5, Number 1, January-March.

Weinhardt, C, Anandasivam A, Blau B, Borissov N, Meinl T, Michalk W, Stober J (2009), Cloud Computing - A Classification, Business Models, and Research Directions, Journal of Business and Information Systems Engineering.

Weinhardt, C., Anandasivam, A., Blau, B. and StoBer, J. (2009). Business Models in the Service World, IEEE Computer Society selected paper, March/April, 1520-9202/09.

Zirpins, C. and Emmerich, W. (2008). A reference model of virtual service production networks, International Journal on Service Oriented Computing and Applications, 2(2-3), pp. 145-166, Springer.

\section{About the author}

Dr Victor Chang was an IT Lead in one of NHS Trusts, UK. He had been as a Senior Lecturer at Leeds Beckett University since September 2012. He will be an Associate Professor at Xi'an Jiaotong Liverpool University, China. He worked as an Assistant Professor and IT Architect at Business School, University of Greenwich, while doing and completing his part-time $\mathrm{PhD}$ research with the University of Southampton. He helps organizations in achieving good Cloud design, deployment and services. He has 27 publications in his $\mathrm{PhD}$, and offers $100 \%$ effort for his full-time work. He has more than 100 peer-reviewed papers. $\mathrm{He}$ is the EIC of ?IJOCI and OJBD journals, an Editor of FGCS journal, reviewers of numerous prestigious journals and a founding conference chair for IoTBD 2016 and COMPLEXIS 2016. With 16 years of IT experience, he is a very active Cloud practitioner and researcher in England, and an international expert on Cloud, Big Data and Security. 